\title{
Measuring dynamics of risk and performance of sector indices on Zagreb Stock Exchange
}

\author{
Tihana Škrinjarić \\ Faculty of Economics and Business, University of Zagreb, Zagreb, Croatia \\ tskrinjaric@efzg.hr
}

\begin{abstract}
Investors are interested in sector diversification on stock markets among other important portfolio topics. This paper looks at five sector indices on Croatian capital market as an example of a small, relatively illiquid market. Sector indices have been constructed at the beginning of 2013 and since then there is a lack of studies, which focus on sector diversification on Zagreb Stock Exchange (ZSE). Thus, the purpose of this paper is to evaluate the recent dynamics of risk and performance of five sector indices on ZSE by employing MGARCH (Multivariate Generalized Autoregressive Conditional Heteroskedasticity) models empirically. Output from the analysis is used to form guidance for investors on Croatian capital market. The results indicate that in the observed period from February 4th 2013 to October 13th 2015 portfolios based on MGARCH methodology outperform other portfolios in terms return and risk. Thus, it is advisable to use this methodology when making portfolio selection.
\end{abstract}

Keywords: MGARCH, Croatian capital market, time varying risk, beta, performance measurement.

JEL classification: G11, C58, C32.

DOI: 10.1515/crebss-2016-0003

Received: October 12, 2015

Accepted: December 3, 2015

\section{Introduction}

There exist many different models and methods in quantitative finance today in order to give answers to different investors' questions. Many of them are developed in order to explain different financial market special features, which differentiate them from other markets. Investors deal with portfolio rebalancing and risks on a daily basis and that is why they need high quality information on financial assets movements regarding return and risk. In the last three decades, there has been a rise of special class of financial econometrics models, which are found to capture financial market co-movements of returns and volatilities - MGARCH (Multivariate Generalized Autoregressive Conditional Heteroskedasticity) models successfully. These models have become very popular in modeling because of their abilities to capture financial market dynamics better compared to other (mostly linear) models (see Aielli 2013, Alexander 2008, Lüketpohl 2006). Moreover, they have been used extensively in the past decade for financial and other assets such as stocks, bonds, 
exchange rates, commodities, etc. Developed markets were the first ones explored, which is not surprising due to the great number of assets, which could be analyzed on them. In the last couple of years, markets in development are in the spotlight as well. However, by looking at the previous literature, it can be seen that the majority of the papers either test for presence of co-movements of returns and volatilities in one country by using MGARCH models or they focus on volatility spillovers between countries (Baumöhl, Liócsa, 2014, Longin, Solnik, 2001, Gelos, Sahay, 2001, Horvath, Petrovski, 2013, Kenaurgios, Samitas, 2011, Syallignakis, Kouretas, 2011, Wang, Moore, 2008). Baumöhl and Liócsa (2014) looked at 8 European emerging markets and $\mathrm{MSCl}$ World market index for the period from 2000 to 2012. They focused on asymmetry and the results indicated that there exists asymmetry in volatility on few markets, but the asymmetry in correlations is existed only on one market. Longin and Solnik (2001) focused on 7 countries in the period 1960-1990. The main result in their analysis was that return correlations were not constant over time. As volatility gets bigger on markets, the correlation rises. Gelos and Sahay (2001) examined financial comovements of European transition economies and found structural breaks on exchange markets. Horvath and Petrovski (2013) also focused on similar countries (Czech Republic, Hungary, Poland, Croatia, Macedonia and Serbia). The period they looked was 2006 to 2011, and found that CEE countries were more correlated than South Eastern European countries. Kenaurgios and Samitas (2011) were interested in five Balkan emerging markets and European developed markets, along with the US market. It was found that long run cointegration between Balkan and developed markets, as well as among Balkan markets themselves. Syallignakis and Kouretas (2011) have examined 7 CEE countries, US, German and Russian market in the period from 1997 to 2009. Main results indicated that market correlations rise in crisis. Moreover, CEE markets are exposed to external shocks from developed markets. Wang and Moore (2008) also focused on three CEE markets. In the period from 1994 to 2006, it was found that correlations rise in crisis periods.

There is a lack of studies, which try to utilize the results from these models in order to give guidance to (potential) investors on how to act on financial markets. This guidance is very important in portfolio management because investors are focused on achieving returns, as well as on managing risks. If they are able to model and financial asset risks and returns, it will enable them to form trading strategies which could beat the market. Any possibility which could provide achieving above average returns and (or) minimize risks is more than welcome on financial markets. This is especially true in times when financial crisis occurs. MGARCH methodology could be very helpful in giving some answers to such questions. In that way, this study is going to utilize aforementioned methodology in order to analyze financial asset risk and return in a more detailed way compared to standard GARCH methodology when analyzing financial assets. More information on financial assets is always welcomed in portfolio analysis when making investment decisions.

Every time a financial crisis hits the markets, the focus of academics and investors is shifted again more towards risks and performances of financial assets. The last crisis in 2008 has affected many markets and investors became more prudent after it. This is especially true for the Croatian capital market (Škrinjarić, Besek, 2014). Analysis in this study is going to look at the Croatian market as an example of a small illiquid market and try to fill the gap in existing research. Up until now, the majority of research on Croatian capital market has implicitly assumed that performance measures, return and risk co-movements were not dynamic over time. This can be seen by observing models in which only averages over the entire period have been used in the analysis (see Škrinjarć, Besek, 2014, for an overview of previous literature). 
Only two papers up until now have used MGARCH models in order to give answers to some of the mentioned issues. Škrinjarić (2015) focused on time varying betas on Croatian capital market, whilst Škrinjarić and Šego (2015) focused only on two assets: stocks and bonds. Thus, the purpose of this paper is to use advantages of dynamics in MGARCH models in order to estimate changing performance and risk measures on Zagreb Stock Exchange in a more detailed way. In that way, recommendations can be made regarding optimal portfolio investing and managing risks. Previous foreign literature, which utilizes this methodology, mostly focuses on investors as international investors. However, sector diversification is important to investors as well, but there exists a scarcity of papers, which observe sector diversification (Hassan, Malik, 2007, Ho, Tsui, 2004, Katzke, 2013, Righia, Ceretta, 2012). Hassan and Malik (2007) looked ad US sectors in the period from 1992 to 2005. They found significant transmissions of volatilities in six sectors. The methodology they used was found useful for forecasting and improving the accuracy of asset pricing models. Ho and Tsui (2004) focused on sector indices in Japan and found asymmetric effects in volatilities, volatility persistence in the period from 1983 to 2003 . Katzke (2013) analyzed economic sectors in South Africa in the period 2002-2013. He found that domestic and global uncertainty influence short run dynamics of comovements between the sectors. Righia and Ceretta (2012) examined financial and consumer sector on Brazilian stock market from 2008 to 2010. The results indicated that there exists bilateral transmission of volatility. All of these papers concluded that MGARCH methodology is useful in portfolio selection. However, they do not provide concrete guidance on how, when and in which financial asset to invest in order to conduct successful portfolio management.

This study is going to focus on sector diversification in order to explore optimal portfolio possibilities on Croatian capital market in a dynamic context. Moreover, it will try to give useful guidance on how to successfully manage portfolios on Zagreb Stock Exchange. The paper is structured as follows. Second section explains the methodology used in the study. Section three reports the results from the empirical analysis, and final, fourth section concludes the paper with recommendations based upon previous results.

\section{Methodology}

Models within MGARCH methodology assume that volatilities of financial asset returns have affect one on another, which is based upon the previous experience of researchers on financial markets. Thus, it is assumed that financial returns and their volatilities move together and MGARCH models capture these dynamics over time (Longin, Solnik, 1995, 2001). There exist a great number of different models within this methodology, but this paper is utilizing the Dynamic and Constant Conditional Correlation models (DCC, CCC) because previous research on these topics has found them to be successful in capturing financial markets movements. Moreover, first two generations of MGARCH models require estimation of a greater number of parameters, which could make the estimation procedure infeasible. DCC and CCC models are more parsimonious and that is why they are popular.

Bollerslev (1990) developed the CCC model in which it is assumed that the correlations between financial asset returns are constant:

$$
\left.\begin{array}{l}
\boldsymbol{r}_{t}=\Theta \boldsymbol{x}_{t}+\boldsymbol{\varepsilon}_{t} \\
\boldsymbol{\varepsilon}_{t}=\boldsymbol{\Omega}_{t}^{\frac{1}{2}} \boldsymbol{u}_{t} \\
\boldsymbol{\Omega}_{t}=\boldsymbol{D}_{t}^{\frac{1}{2}} \boldsymbol{R} \boldsymbol{D}_{t}^{\frac{1}{2}}
\end{array}\right\},
$$


in which $\boldsymbol{r}+$ is the $(m, 1)$ vector of returns, $\boldsymbol{\Theta}(m, k)$ matrix of parameters, $\mathbf{x}+(k, 1)$ vector of independent variables, $\boldsymbol{\varepsilon} t(m, 1)$ vector of innovation processes. $\Omega_{t}^{1 / 2}$ is the Cholesky factor $(m, m)$ matrix of the conditional covariance matrix $\boldsymbol{\Omega}_{+}(m, m), \mathbf{u}_{+}$is $(m, 1)$ vector of normal i.i.d. innovations, $\boldsymbol{D}_{+}(m, m)$ diagonal matrix of conditional variances and $\boldsymbol{R}$ is $(m, m)$ positive definite unconditional correlation matrix. Usually, the assumption of multivariate normal distribution of $\boldsymbol{u}_{+}$are made, because correctly specifying the conditional mean and variances results with consistent estimates (Engle, 2009). Variances in matrix $D_{+}$are modeled by univariate GARCH $(1,1)$ models: $\sigma_{i, t}^{2}=\alpha_{0, i}+\alpha_{1, i} \varepsilon_{i, t-1}^{2}+\beta_{1, i} \sigma_{i, t-1}^{2}$. In order for conditional variances to be positive, it must hold that: $a_{0, i}>0, a_{1, i \geq 0}$ and $\beta_{1, i \geq 0}$; and in order for them to be finite, it must hold that $a_{1, i}+\beta_{1, i}<1$.

Since it is often not reasonable to assume that correlations between financial asset returns are constant, Engle (2002) developed the DCC model:

$$
\left.\begin{array}{l}
\boldsymbol{r}_{t}=\Theta \boldsymbol{x}_{t}+\boldsymbol{\varepsilon}_{t} \\
\boldsymbol{\varepsilon}_{t}=\boldsymbol{\Omega}_{t}^{\frac{1}{2}} \boldsymbol{u}_{t} \\
\boldsymbol{\Omega}_{t}=\boldsymbol{D}_{t}^{\frac{1}{2}} \boldsymbol{R}_{t} \boldsymbol{D}_{t}^{\frac{1}{2}} \\
\boldsymbol{R}_{t}=\operatorname{diag}\left(\boldsymbol{Q}_{t}\right)^{-\frac{1}{2}} \boldsymbol{Q}_{t} \operatorname{diag}\left(\boldsymbol{Q}_{t}\right)^{-\frac{1}{2}} \\
\boldsymbol{Q}_{t}=\left(1-\theta_{1}-\theta_{2}\right) \boldsymbol{R}+\theta_{1} \tilde{\boldsymbol{\varepsilon}}_{t-1} \tilde{\boldsymbol{\varepsilon}}_{t-1}^{\prime}+\theta_{2} \boldsymbol{Q}_{t-1}
\end{array}\right\},
$$

where $\boldsymbol{R}_{\dagger}$ is $(m, m)$ matrix of conditional correlations. $Q_{+}$is $(m, m)$ variance and covariance matrix of standardized innovations, $\tilde{\varepsilon}_{t}(m, 1)$ vector of standardized innovations, $\tilde{\boldsymbol{\varepsilon}}_{t}=\boldsymbol{D}^{-1} \boldsymbol{\varepsilon}$, and $\boldsymbol{R}(\mathrm{m}, \mathrm{m})$ positive definite unconditional correlation matrix. The dynamics of conditional correlations is defined by nonnegative scalars $\theta_{1}$ and $\theta_{2}$. It must hold $\theta_{1}+\theta_{2}<1$ for the model to be stationary (Engle, 2002, 2009). Ding and Engle (2004) add that standardized innovations satisfy $E\left(\tilde{\varepsilon}_{t} \tilde{\varepsilon}_{t}^{\prime}\right)=I_{m}$, where $I_{m}$ is the identity matrix, $\operatorname{Cov}\left(\tilde{\varepsilon}_{i, t}^{2}, \tilde{\varepsilon}_{j, t}^{2}\right)=0 \forall i \neq j$, and $\operatorname{Cov}\left(\tilde{\varepsilon}_{i, t}^{2}, \tilde{\varepsilon}_{j, t-k}^{2}\right)=0, k>0$. It can easily be seen that if $\theta_{1}=\theta_{2}=0$ holds, DCC model becomes CCC model. Models are estimated in two steps: in the first step, univariate GARCH models are estimated with respect to alphas and betas. In the second step, the rest of the model is estimated with estimated parameters from the first step, with respect to $\theta_{1}$ and $\theta_{2}$. For more details see Aielli (2013), Alexander (2008), Ang, Chen (2005), Bollerslev (1990), Bollerslev, Wooldridge (1992), Lüketpohl (2006).

Results from these models can be used in a number of ways. This paper is focused on performance measures of indices on Croatian stock market. That is why we are focusing on beta, Sharpe ratio, RAPA measure, Treynor ratio, Jensen's alpha and Value at Risk. Beta is a well known concept from CAPM model (Sharpe, 1964, Lintner, 1965). Here, we assume that it is time varying, defined as the following ratio:

$$
\beta_{i, t}=\frac{\operatorname{cov}_{i, t}\left(r_{i, t}, r_{M, t}\right)}{\sigma_{M, t}^{2}},
$$

where $\beta_{i, t}$ is time varying beta of $i$-th stock, $r_{i, t}$ excess return on the $i$-th stock and $r_{M, t}$ excess market return in time $t$. Jensen's alpha (1967) is also a concept from CAPM model in which it is defined as abnormal return of financial asset (or portfolio) over theoretical expected return. It is calculated as follows:

$$
\alpha_{i, t}=r_{i, t}-\beta_{i, t} r_{M, t} \text {. }
$$

Sharpe ratio (1966) is another measure of performance, in which the excess return is standardized by return's standard deviation: 


$$
\text { Sharpe }_{i, t}=\frac{r_{i, t}}{\sigma_{i, t}} .
$$

It gives information on how much individual stock (or index) achieves return by given one percent level of risk. RAPA ratio (Modigliani, 1997) is a modification of the Sharpe ratio, by using standard deviation of stock market return as a modification factor:

$$
R A P A_{i, t}=\text { Sharpe }_{i, t} \cdot \sigma_{M, t} \text {. }
$$

It also measures risk-adjusted performance, but here we also adjust for stock market risk as well. Treynor ratio (Treynor, 1965) is a risk adjusted measure as well, similar to the Sharpe ratio. This ratio standardizes returns by using beta as a measure of risk (systematic risk only):

$$
\text { Treynor }_{i, t}=\frac{r_{i, t}}{\beta_{i, t}} .
$$

Finally, Value at Risk measure will be considered as a concept of measuring maximal loss investors can face in certain time period with level of certainty $\gamma$ :

$$
\operatorname{VaR}_{i, t}=\Phi^{-1}(1-\gamma) \sigma_{i, t}-E\left(r_{i, t}\right),
$$

where $\Phi^{-1}$ is the inverse distribution function of standardized normally distributed random variable (see Alexander, 2008, for the derivation of expression (8)). All of the mentioned measures are often used as guidance on how to invest funds into different financial assets. However, in the past literature, they were used as static measures in the majority cases. Next section is going to look at all of these measures on a daily basis because of financial market dynamics.

\section{Empirical research}

For the purpose of the empirical research, daily data on five sector indices and stock market index CROBEX has been collected from ZSE (2015) for the period from February $4^{\text {th }} 2013$ to October 13 $13^{\text {th }} 2015$. Data on 91 day Treasury bill interest rates has been collected from GFD (Global Financial Data, 2015) and excess returns have been calculated by extracting the 91 day Treasury bill interest rate from the original return series. Broad indices were considered as guidance for what is happening in each sector on the market, as previous research uses such indices as well. Moreover, a short time span is used because these indices are calculated since the beginning of 2013 and no other data on them is available before that date.

Table 1 Descriptive statistics of each sector

\begin{tabular}{|l|r|r|r|r|r|r|r|}
\hline \multicolumn{1}{|c|}{$\begin{array}{c}\text { Sector / } \\
\text { statistics }\end{array}$} & \multicolumn{1}{c|}{ Mean } & \multicolumn{1}{c|}{ Median } & Max. & \multicolumn{1}{c|}{ Min. } & $\begin{array}{r}\text { Standard } \\
\text { deviation }\end{array}$ & Skewness & Kurtosis \\
\hline Crobex & -0.0002 & -0.0004 & 0.018 & -0.030 & 0.005 & -0.118 & 5.002 \\
Industry & $-4.17 \cdot 10^{-5}$ & $5.68 \cdot 10^{-5}$ & 0.071 & -0.100 & 0.013 & -0.571 & 1.078 \\
Construction & -0.001 & -0.002 & 0.077 & -0.099 & 0.017 & 0.160 & 5.694 \\
Food & -0.0005 & -0.0004 & 0.044 & -0.043 & 0.008 & 0.272 & 5.933 \\
Transportation & $-9.28 \cdot 10^{-5}$ & -0.0007 & 0.047 & -0.055 & 0.013 & 0.161 & 3.816 \\
Tourism & 0.001 & 0.001 & 0.079 & -0.060 & 0.013 & 0.652 & 7.011 \\
\hline
\end{tabular}

Source: author's calculation.

First of all, descriptive statistics was calculated for each return series and the results are given in Table 1. If we observe the descriptive statistics for the entire period for each return series, several conclusions can be made. On average, construction sector had the biggest loss and tourism was the only sector with the average positive return. Only three sectors performed better than the stock market (industry and 
transportation, besides tourism). Most volatile sector was construction by comparing standard deviations, and the market as a whole was safer compared to individual sectors. Coefficients of skewness and kurtosis give information on the occurrence of extreme positive and negative returns: tourism was once again better compared to other sectors and the market because investors could have achieved greater above average returns compared to extreme below average ones. However, the information given in Table 1 is only averaged.

Before estimating models described in the previous section, unit root tests were performed on all return series and all returns were found to be stationary on usual levels of significance. DCC GARCH $(1,1)$ has been estimated for each sector and index CROBEX. However, parameters $\hat{\theta}_{1}$ and $\hat{\theta}_{2}$ were found to be statistically not significant for industry, construction and transportation sector. That is why CCC $\operatorname{GARCH}(1,1)$ has been estimated for those three sectors. Moreover, parameter $\hat{\alpha}_{1}$ in univariate GARCH $(1,1)$ specification of transportation return was found to be negative so GARCH $(0,1)$ has been estimated in that case. Detailed results from estimation are given in Table 2. As it can be seen, sector returns, which react mostly to market innovation shocks, are industry and food sector (alphas $\hat{\alpha}_{1, i}$ ). Most persistent volatilities are those of transportation and tourism. These conclusions can be seen on Figures 1-5, which show conditional variances of each return series from estimated models in Table 2. This is useful information for portfolio risk managing when a shock occurs on the market. Those sectors with persistent volatility could be avoided when external shock hits the market.

Table 2 MGARCH estimation results for each sector

\begin{tabular}{|c|c|c|c|c|c|c|}
\hline & CROBEX & Industry & Construction & Food & Transportation & Tourism \\
\hline$\hat{\mu}_{i}$ & -0.0002 & $-4.35 \cdot 10^{-5}$ & $-0.001^{*}$ & $-0.001^{*}$ & -0.0001 & $0.001^{* * *}$ \\
\hline$\hat{\alpha}_{0, i}$ & $1.3 \cdot 10^{-6} * *$ & $3.21 \cdot 10^{-5 * * *}$ & $6.30 \cdot 10^{-5}$ *** & $6.35 \cdot 10^{-6 * *}$ & $2.5 \cdot 10^{-5}$ & $1.41 \cdot 10^{-5}$ \\
\hline$\hat{\alpha}_{1, i}$ & $0.033^{* * *}$ & $0.130^{* * *}$ & $0.111^{* * *}$ & $0.120^{* * *}$ & - & $0.091^{* *}$ \\
\hline$\hat{\beta}_{1, i}$ & $0.913^{* * *}$ & $0.685^{* * *}$ & $0.677^{* * *}$ & $0.792^{* * *}$ & $0.854^{* *}$ & $0.824^{* * *}$ \\
\hline$\hat{\rho}_{i, \text { crobex }}$ & - & $0.404^{* * *}$ & $0.275^{* * *}$ & - & $0.274^{* * *}$ & \\
\hline$\hat{\theta}_{1, i}$ & - & - & - & $0.036^{* *}$ & - & $0.034^{* * *}$ \\
\hline$\hat{\theta}_{2, i}$ & - & - & - & $0.864^{* * *}$ & - & $0.932^{* * *}$ \\
\hline $\log L$ & - & 4630.07 & 4397.68 & 4937.74 & 4564.15 & 4599.00 \\
\hline SIC & - & -13.754 & -13.060 & -14.653 & -13.577 & -13.642 \\
\hline HQIC & - & -13.791 & -13.097 & -14.699 & -13.606 & -13.687 \\
\hline $\mathrm{AlC}$ & - & -13.815 & -13.120 & -14.728 & -13.624 & -13.716 \\
\hline
\end{tabular}

Note: $\hat{\mu}_{i}$ is the estimated value of average return, $\hat{\alpha}_{0, i}, \hat{\alpha}_{1, i}$ and $\hat{\beta}_{1, i}$ parameters in univariate GARCH specifications, $\hat{\rho}_{i, c r o b e x}$ estimated correlation coefficient for each sector and CROBEX and $\hat{\theta}_{1, i}$ and $\hat{\theta}_{2, i}$ are estimated parameters in DCC GARCH $(1,1)$ models. Log $L$ stands for log likelihood, SIC, HQIC and AlC stand for Schwartz, Hannan-Quinn and Akaike information criteria respectively. ${ }^{*},{ }^{* *}$ and ${ }^{* * *}$ stand for statistical significance on $10 \%, 5 \%$ and $1 \%$ level respectively. Tests for multivariate autocorrelation of standardized returns and multivariate heteroskedasticity of standardized returns up to lag 30 have shown that there is no autocorrelation and no heteroskedasticity on usual levels of significance. Correlation coefficients of standardized residuals, covariances and covariances between squared residuals up to lag 30 of standardized residuals are not statistically significant. Strict positivity of variances is ensured by positive values of estimated parameters in univariate GARCH equations. Conditional variances are finite which is ensured by the condition $\hat{\alpha}_{1, i}+\hat{\beta}_{1, i}<1$ in each univariate GARCH equation. Source: author's calculation. 
V_CONSTRUCTION

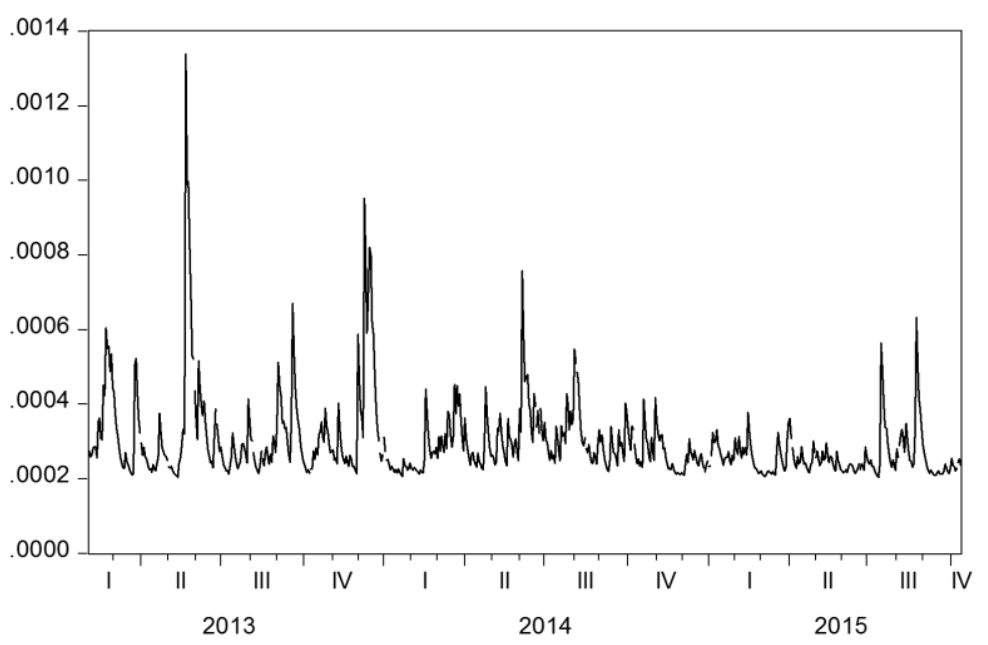

Figure 1 Conditional variance of construction return series Source: author's calculation.

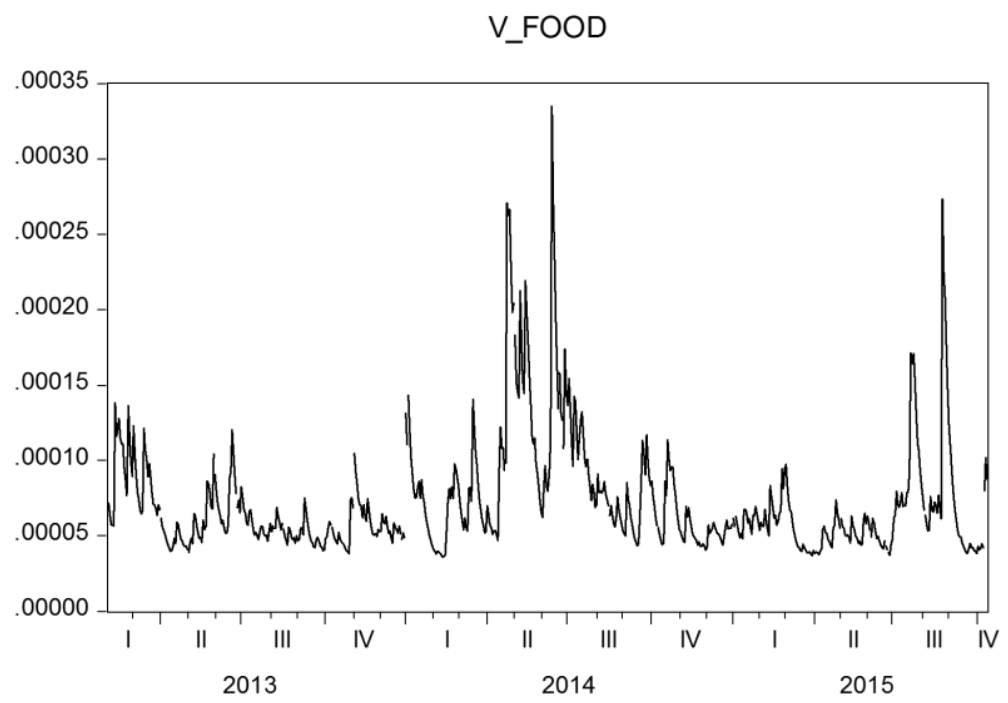

Figure 2 Conditional variance of food return series Source: author's calculation.

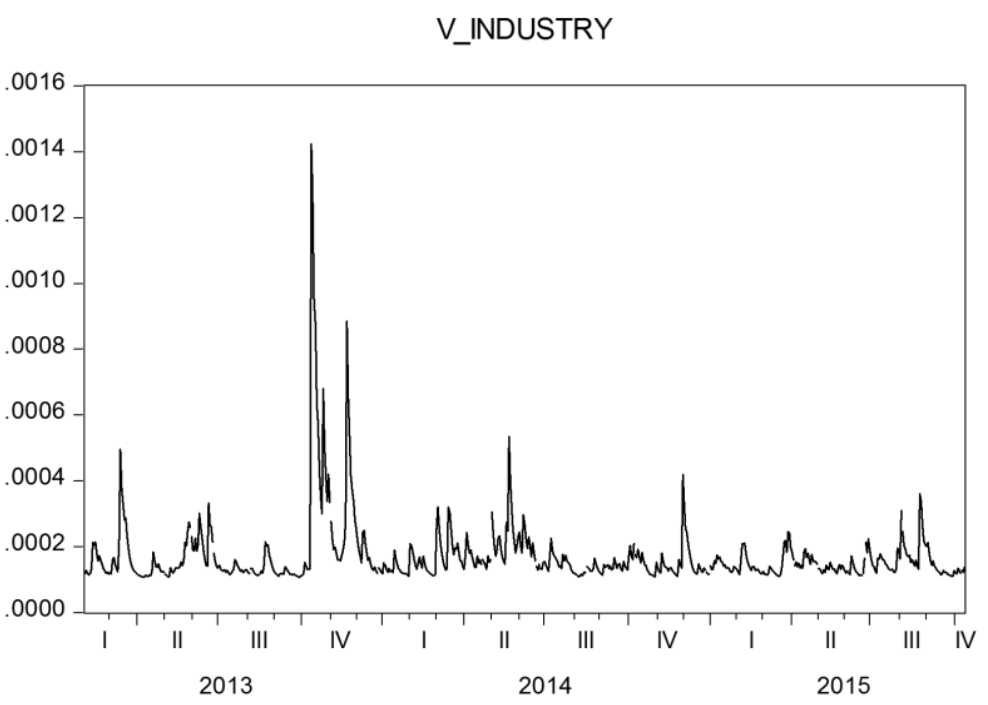

Figure 3 Conditional variance of industry return series Source: author's calculation. 
V_TOURISM

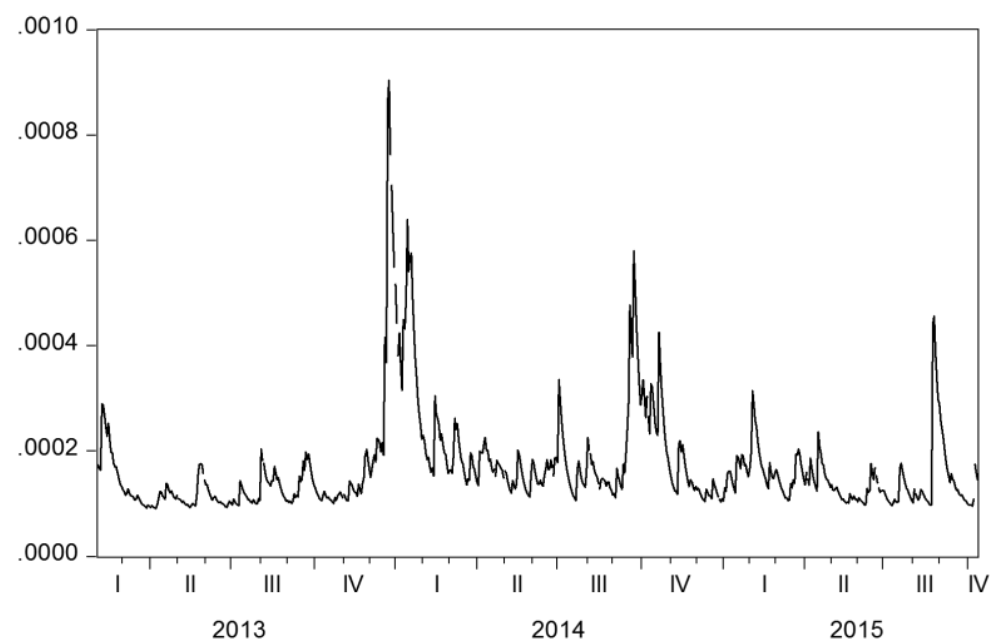

Figure 4 Conditional variance of tourism return series Source: author's calculation.

V_TRANSPORTATION

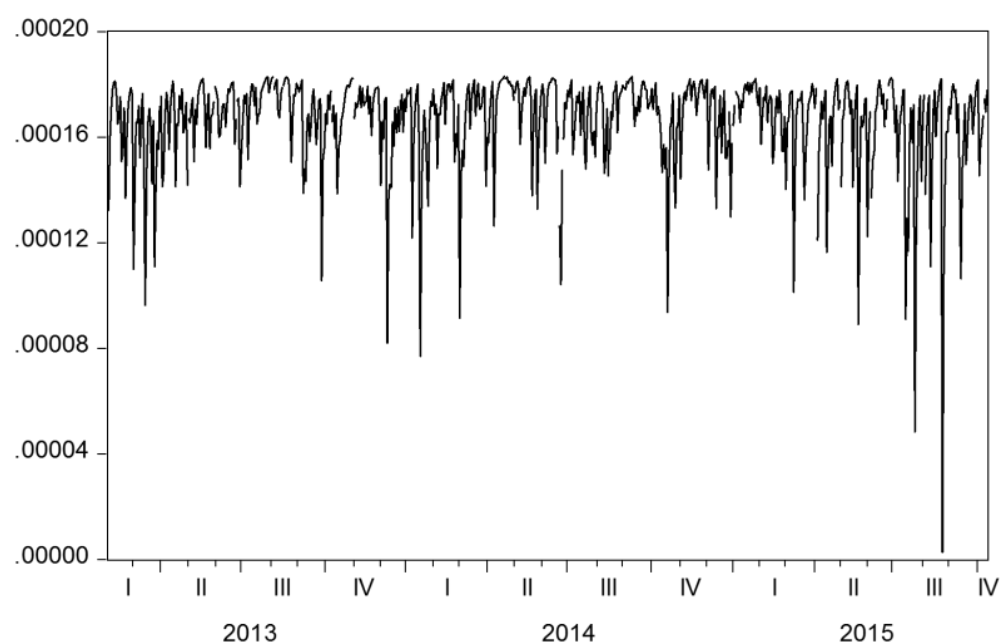

Figure 5 Conditional variance of transportation return series Source: author's calculation.

Estimated results can now be used to calculate time-varying performance measures for each sector return. First of all, CAPM betas have been calculated as ratios given in (3) and are shown on Figures 6-10. It can be seen that industry and construction betas are most volatile in the observed period, which could attract aggressive investors. On the other hand, transportation and food betas show that these sectors were more attractive for conservative investors. 


\section{B_CONSTRUCTION}

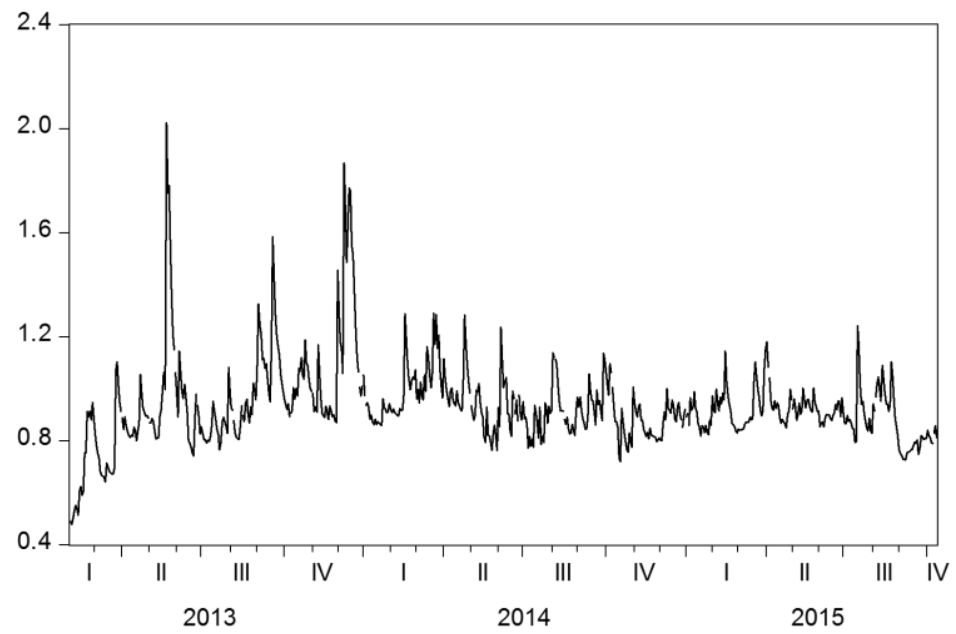

Figure 6 Time varying CAPM beta for construction sector Source: author's calculation.

B_FOOD

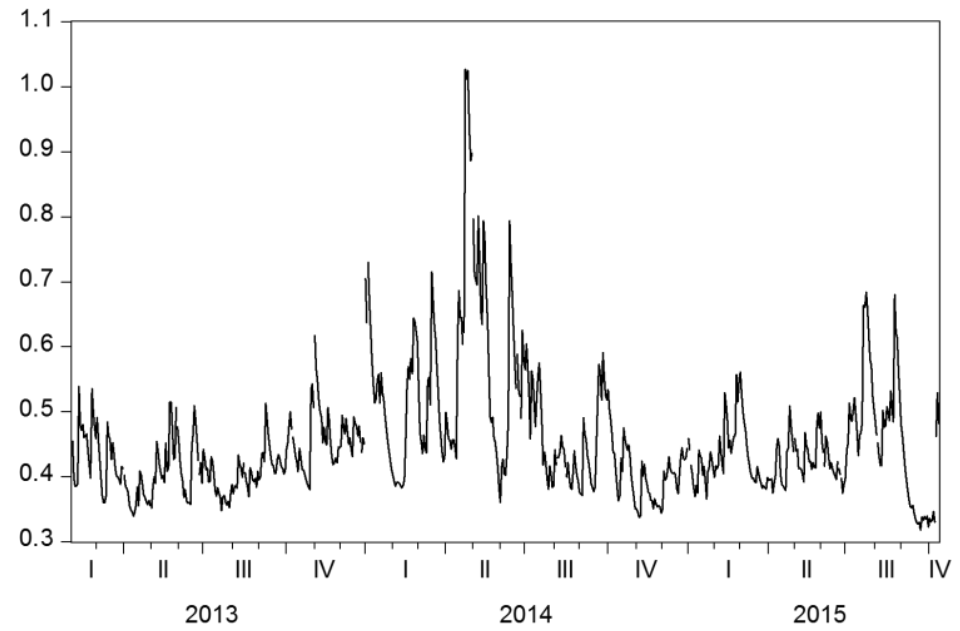

Figure 7 Time varying CAPM beta for food sector Source: author's calculation.

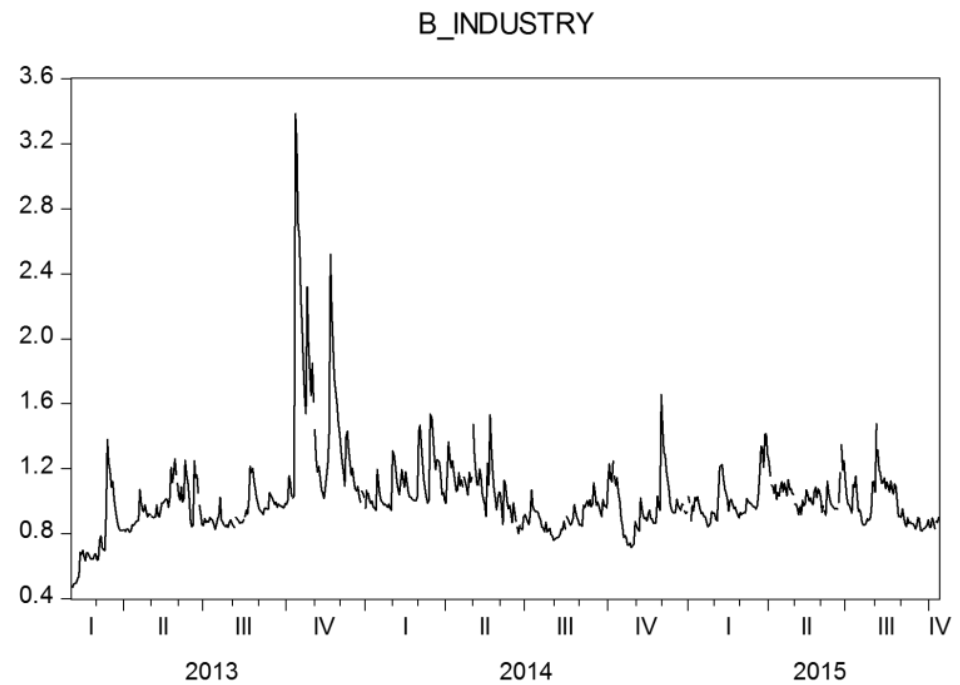

Figure 8 Time varying CAPM beta for industry sector Source: author's calculation. 
B_TOURISM

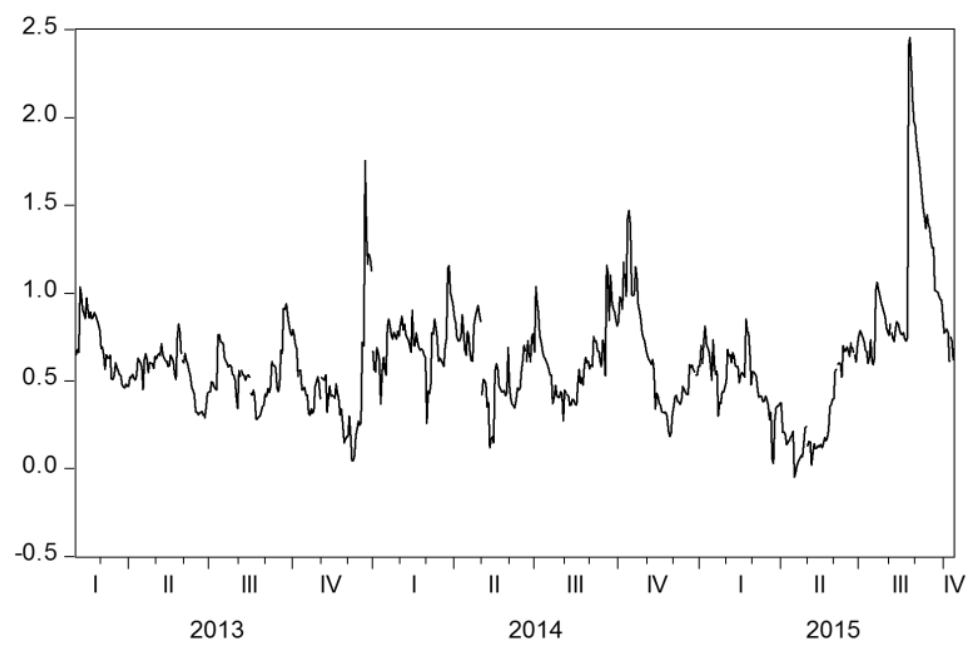

Figure 9 Time varying CAPM beta for tourism sector Source: author's calculation.

B_TRANSPORTATION

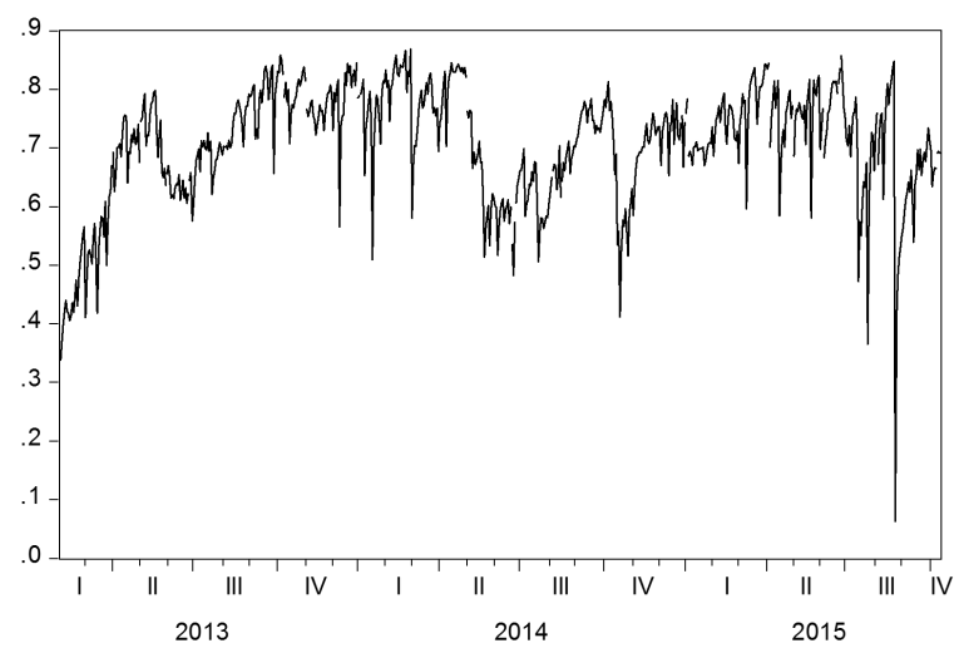

Figure 10 Time varying CAPM beta for tourism sector Source: author's calculation.

Next, other performance measures given in (4)-(8) have been calculated in order to compare five sectors and descriptive statistics for each measure is summarized in Table 2. First of all, the Sharpe ratio indicates that on average, tourism sector had the biggest standardized return, which means that this sector achieved the biggest return on equal level or risk compared to others. Greatest standardized return could have been achieved in construction sector (which is not surprising due to its aggressiveness) and transportation sector provided minimal loss (again, not surprising because it was found to be conservative). RAPA measure gives us similar conclusions, since it is calculated by using the Sharpe ratio. However, it considers sector's relative riskiness to stock market risk and in that way, it is more comparable among sectors. By observing sector alphas, tourism is again the best performing sector, whilst the most of benefits could have been achieved in construction sector in good times (positive alpha) and food sector in bad times (realizing smaller losses with least negative alpha). The Treynor ratio takes into account systematic risk compared to Sharpe ratio. That is why conclusions for best and worst sector differ. 
Since food sector was found to be conservative, it is not surprising that looking at Value at Risk, it provided the least loss for potential investors.

Overall, looking at sectors, which performed worst, construction and industry, had such performance that although investors could benefit from them in good times, they could achieve great losses as well. This is not surprising due to the results from MGARCH models in which it was found that these sectors are most aggressive ones. Ones that are more conservative were food, tourism and transportation. This is in accordance with conclusions given in Škrinjarić (2015). Inclusive, the analysis based upon Table 3 can provide useful guidance on a daily basis in order to minimize risks and to achieve above average returns.

Table 3 Descriptive statistics of performance measures

\begin{tabular}{|c|c|c|c|c|c|c|}
\hline Measure & Statistics & Construction & Food & Industry & Tourism & Transportation \\
\hline \multirow{3}{*}{$\begin{array}{l}\text { Sharpe } \\
\text { ratio }\end{array}$} & Mean & -0.075 & -0.058 & -0.003 & 0.114 & -0.006 \\
\hline & Maximum & 4.370 & 4.126 & 4.291 & 4.120 & 3.563 \\
\hline & Minimum & -5.521 & -5.482 & -8.731 & -6.101 & -4.088 \\
\hline \multirow{3}{*}{ Alpha } & Mean & -0.001 & מח९ ח & 0.0002 & 0.002 & $7.03 \cdot 10^{-5}$ \\
\hline & Maximum & 0.079 & 0.037 & 0.0634 & 0.076 & 0.046 \\
\hline & Minimum & -0.092 & -0.029 & -0.096 & -0.051 & -0.038 \\
\hline \multirow{3}{*}{ Rapa } & Mean & -0.0004 & 00003 & $4.35 \cdot 10^{-5}$ & 0.0007 & $1.87 \cdot 10^{-5}$ \\
\hline & Maximum & 0.021 & 0.029 & 0.022 & 0.028 & 0.019 \\
\hline & Minimum & -0.027 & -0.024 & -0.039 & -0.027 & -0.018 \\
\hline \multirow{3}{*}{ Treynor } & Mean & -0.001 & -0.001 & 0.0001 & 0.0006 & $8.41 \cdot 10^{-5}$ \\
\hline & Maximum & 0.075 & 0.090 & 0.055 & 0.456 & 0.069 \\
\hline & Minimum & -0.099 & -0.089 & -0.097 & -0.570 & -0.065 \\
\hline \multirow{2}{*}{ VaR } & Mean & -0.029 & -0.014 & -0.021 & -0.019 & -0.021 \\
\hline & Maximal loss & -0.128 & -0.056 & -0.119 & -0.091 & -0.077 \\
\hline
\end{tabular}

Note: bolded numbers indicate the best sector and italic ones indicate the worst sector. Source: author's calculation.

Furthermore, a couple of portfolios have been simulated in order to compare their performances based upon the results from MGARCH methodology. Return on CROBEX is used as a representative of market return in order to have a benchmark to compare MGARCH portfolios. Average portfolio is used as a benchmark as well as a simple trading strategy. In that way, CROBEX and average portfolio represent trading strategies in which investors do not take into account the dynamics in return and volatilities. Three portfolios have been simulated based upon the results in Table 1: aggressive one, in which investor holds two aggressive indices: industry and construction, conservative one, in which investor holds tourism, food and transportation sectors; and the beta based portfolio in which investor holds the index with the greatest beta when the market is bullish and when the market is bearish, he holds the index with the smallest beta. All performance measures, which have been calculated for each sector return, have been calculated for portfolios as well, and are given in Table 4. By looking at the results, it seems that the conservative portfolio outperformed others based upon almost all measures (beta and VaR are exceptions). The worst portfolio was the aggressive one. Moreover, majority of the portfolios outperform the stock market return as well. However, these results are only averaged, so another comparison has been made, by making a distinction of the market on bearish and bullish. The results are given in Table 5 and Table 6 . 
Table 4 Average performance of simulated portfolios

\begin{tabular}{|c|c|c|c|c|r|}
\hline & \multicolumn{5}{|c|}{ Portfolio } \\
\cline { 2 - 6 } & Average & Aggressive & Conservative & Beta based & CROBEX \\
\hline Return & -0.0001 & -0.0006 & $\mathbf{0 . 0 0 0 3}$ & 0.0002 & -0.0002 \\
Beta & 0.7474 & $\mathbf{0 . 9 8 0 9}$ & 0.5918 & 0.7317 & 1.0000 \\
Sharpe & -0.0052 & -0.0380 & $\mathbf{0 . 0 1 6 7}$ & -0.0201 & -0.0468 \\
RAPA & 0.0000 & -0.0002 & $\mathbf{0 . 0 0 0 1}$ & 0.0000 & - \\
Treynor & -0.0003 & -0.0006 & $\mathbf{- 0 . 0 0 0 1}$ & -0.0026 & - \\
VaR & -0.0210 & -0.0251 & -0.0183 & -0.0227 & $\mathbf{- 0 . 0 0 8 6}$ \\
Alpha & 0.0001 & -0.0004 & $\mathbf{0 . 0 0 0 4}$ & -0.0002 & 0.0000 \\
\hline
\end{tabular}

Note: bolded numbers indicate the best sector and italic ones indicate the worst sector. Source: author's calculation.

Table 5 Performance of simulated portfolios in bear market

\begin{tabular}{|c|c|c|c|c|r|}
\hline & \multicolumn{5}{|c|}{ Portfolio } \\
\cline { 2 - 6 } & Average & Aggressive & Conservative & Beta based & CROBEX \\
\hline Return & -0.0029 & -0.0015 & $-\mathbf{0 . 0 0 0 4}$ & -0.0026 & -0.0039 \\
Beta & 0.7525 & 0.9848 & 0.5977 & $\mathbf{0 . 4 0 9 2}$ & 1.0000 \\
Sharpe & -0.0649 & -0.0982 & $\mathbf{- 0 . 0 4 2 7}$ & -1.1023 & -0.7701 \\
RAPA & -0.0003 & -0.0005 & $\mathbf{- 0 . 0 0 0 2}$ & -0.0056 & - \\
Treynor & $-\mathbf{0 . 0 0 1 7}$ & $\mathbf{- 0 . 0 0 1 7}$ & $\mathbf{- 0 . 0 0 1 7}$ & -0.0262 & - \\
VaR & -0.0218 & -0.0260 & $\mathbf{- 0 . 0 1 9 0}$ & -0.0389 & -0.0122 \\
Alpha & -0.0003 & -0.0009 & $\mathbf{0 . 0 0 0 1}$ & -0.0140 & 0.0000 \\
\hline
\end{tabular}

Note: bolded numbers indicate the best sector and italic ones indicate the worst sector. Source: author's calculation.

Table 6 Performance of simulated portfolios in bull market

\begin{tabular}{|c|c|c|c|c|r|}
\hline & \multicolumn{5}{|c|}{ Portfolio } \\
\cline { 2 - 6 } & Average & Aggressive & Conservative & Beta based & CROBEX \\
\hline Return & 0.0031 & 0.0004 & 0.0011 & $\mathbf{0 . 0 0 3 4}$ & 0.0040 \\
Beta & 0.7417 & 0.9765 & 0.5852 & $\mathbf{1 . 0 9 0 9}$ & 1.0000 \\
Sharpe & 0.0614 & 0.0290 & 0.0830 & $\mathbf{1 . 1 8 5 3}$ & 0.7616 \\
RAPA & 0.0004 & 0.0002 & 0.0005 & $\mathbf{0 . 0 0 6 2}$ & - \\
Treynor & 0.0012 & 0.0005 & 0.0017 & $\mathbf{0 . 0 2 3 8}$ & - \\
VaR & -0.0202 & -0.0242 & -0.0175 & $\mathbf{- 0 . 0 0 4 7}$ & -0.0045 \\
Alpha & 0.0005 & 0.0001 & 0.0008 & $\mathbf{0 . 0 1 5 2}$ & 0.0000 \\
\hline
\end{tabular}

Note: bolded numbers indicate the best sector and italic ones indicate the worst sector. Source: author's calculation.

Bear market is in line when stock market returns are negative, and opposite is valid for the bull market. If we want to know if a portfolio is superior to others on the market, we should look at its performance when the market is falling or rising. As it can be seen in Table 5 and Table 6, conservative portfolio outperforms others when the market is bearish, while beta based portfolio is best when the market is bullish. Overall, aggressive portfolio is showing the worst results. This means that in the observed period, on the Croatian capital market when the market was falling, it was better to be conservative in order to lose less compared to others. Moreover, it was favorable to base the portfolio upon time varying betas in order to gain the most. These strategies outperformed the market return and the average portfolio return in the whole observed period. Thus, results indicate that using output from MGARCH methodology is very helpful and useful when forming trading strategies on stock markets. In that way, (potential) investors could benefit by achieving greater returns compared to the market return and other trading strategies, which do not take time 
varying performance measures into account. Moreover, they could manage risks more efficiently by using information from time varying risk measures.

Investors are advised to use return and risk measures on a daily basis, by applying MGARCH methodology. In that way, they could achieve better returns compared to the market return and other trading strategies. Moreover, they could manage portfolio risk in a better way compared to trading strategies, which do not consider MGARCH methodology.

\section{Conclusions}

This paper deals with questions regarding successful portfolio formation in terms of good returns and managing risks. Previous literature showed that financial asset's returns and volatilities could be successfully modeled by using MGARCH methodology. However, there exists scarcity of papers, which utilize the results from this methodology in order to form trading strategies with portfolios, which could beat the market. This paper is an attempt to do such analysis. In that way, performance and risk measures have been calculated on a daily basis in order to rank sector indices on Zagreb Stock Exchange. Based upon the results from dynamic returns and volatilities, indices were classified as aggressive or conservative. Moreover, a couple of portfolios have been constructed and trading strategies have been simulated in order to compare their performances. The results indicate that using information from dynamics of MGARCH models is useful when forming trading strategies. Portfolios formed based upon the output from this methodology have outperformed the market as a whole, as well as average portfolios, in terms of return and risk. Thus, using this methodology could enhance portfolio selection and enable investor to achieve better results compared to trading strategies, which do not take into account mentioned dynamics. However, there were some pitfalls in this study. A relatively short time span was considered because sector indices are measured since 2013 in Croatia. Moreover, only broad indices have been observed. Investors are interested in specific stocks and future research is going to include assets that are more specific. Furthermore, analysis was performed with the assumption of no transaction costs, which could be very high on illiquid markets. That is why future work is going to include this problem as well. However, the preliminary analysis done in this paper is in accordance with previous literature on this topic, which provides us a good starting point for further research.

\section{References}

1. Aielli, G. P. (2013). Dynamic Conditional Correlations: On Properties and Estimation. Journal of Business \& Economic Statistics, Vol. 31, No. 3, pp. 282-299.

2. Alexander, C. (2008). Market Risk Analysis, Volume II: Practical Financial Econometrics. John Wiley \& Sons, Chichester.

3. Ang. A., Chen, J. (2005). CAPM over the long run: 1926-2001. NBER Working Paper Series, National Bureau of Economic Research.

4. Baumöhl, E., Lyócsa, Š. (2014). Volatility and dynamic conditional correlations of worldwide emerging and frontier markets. Economic Modelling, Vol. 38, pp. 175-183.

5. Bollerslev, T. (1990). Modelling the coherence in short-run nominal exchange rates: $A$ multivariate generalized ARCH model. Review of Economics and Statistics, Vol. 72, pp. 498-505.

6. Bollerslev, T., Wooldridge J.M. (1992). Quasi-maximum likelihood estimation and inference in dynamic models with time-varying covariances. Econometric Reviews, Vol. 11, pp. 143172. 
7. Engle, R. F. (2002). Dynamic conditional correlation: A simple class of multivariate generalized autoregressive conditional heteroskedasticity models. Journal of Business \& Economic Statistics, Vol. 20, pp. 339-350.

8. Engle, R. F. (2009). Anticipating Correlations: A New Paradigm for Risk Management. Princeton University Press, New York.

9. Gelos, R.G., Sahay, R. (2001). Financial market spillovers in transition economies. Economics of Transition, Vol. 9, No.1, pp. 53-86.

10.Global Financial Data (2015). GFD Database, Fixed Income Database. Available at https://www.globalfinancialdata.com/GFDPlatform/Login.aspx [15 October 2015].

11.Hassan, S. A., Malik, F. (2007). Multivariate GARCH modelling of sector volatility transmission. The Quarterly Review of Economics and Finance, Vol. 47, pp. 470-480.

12. Ho, K-Y., Tsui, A. K. C. (2004). An Analysis of the Sectoral Indices of Tokyo Stock Exchange: A Multivariate GARCH Approach with Time Varying Correlations. Stochastic Finance, Autumn School and International Conference.

13. Horvath, R., Petrovski, D. (2013). International stock market integration: Central and South Easter Europe compared. Economic Systems, Vol. 37, pp. 81-91.

14.Jensen, M. C. (1967). The Performance of Mutual Funds in the Period 1945-1964. Journal of Finance, Vol. 23, No. 2, pp. 389-416.

15. Katzke, N. (2013). South African Sector Return Correlations: using DCC and ADCC Multivariate GARCH techniques to uncover the underlying dynamics. Stellenbosch Economic Working Papers: 17/13, Universiteit Stellenbosch University.

16.Kenourgios, D., Samitas, A. (2011). Equity market integration in emerging Balkan markets. Research in International Business and Finance, Vol. 25, pp. 296-307.

17.Lintner, J. (1965). The valuation of risk assets and the selection of risky investments in stock portfolios and capital budgets. Review of Economics and Statistics, Vol. 47, No. 1, pp. 1337.

18.Longin F., Solnik B. (1995). Is the correlation in international equity returns constant: 19601990?. Journal of International Money and Finance, Vol. 14, pp. 3-26.

19.Longin F., Solnik B. (2001). Extreme correlation in international equity markets. Journal of Finance, Vol. 56, pp. 649-676.

20.Lüketpohl, H. (2006). New Introduction to Multiple Time Series Analysis. Springer, Berlin.

21.Modigliani, F. (1997). Risk-Adjusted Performance. Journal of Portfolio Management, 1997, pp. 45-54.

22.Righia, M. B., Ceretta, P. S. (2012). Multivariate generalized autoregressive conditional heteroscedasticity (GARCH) modeling of sector volatility transmission: A dynamic conditional correlation (DCC) model approach. African Journal of Business Management, Vol. 6, pp. 8157-8162.

23.Sharpe, W. F. (1964). Capital asset prices: A theory of market equilibrium under conditions of risk. Journal of Finance, Vol. 19, pp. 425-442.

24.Sharpe, W. F. (1966). Mutual Fund Performance. Journal of Business, Vol. 39, pp. 119-138.

25.Syllignakis, M. N., Kouretas, G.P. (2011). Dynamic correlation analysis of financial contagion: Evidence from the Central and Eastern European markets, International Review of Economics and Finance, Vol. 20, pp. 717-732.

26.Škrinjarić, T. (2015). Time varying CAPM betas on Zagreb Stock Exchange, In Proceedings of the 13th International Symposium on Operational Research, Zadnik Stirn, L., Žerovnik, J., Kljajić Borštnar, M., Drobne, S., Eds., Bled, Slovenia, September 23-25, 2015, pp. 413-418.

27.Škrinjarić, T., Besek, B. (2014). Pre and Post Crisis Performance Measurement of Croatian Stock Market. Zagreb International Review of Economics and Business, Vol. 17, pp. 97116.

28.Škrinjarić, T., Šego, B. (2015) Dynamic modeling of stock and bond return correlation in Croatia. In Proceedings of the 13th International Symposium on Operational Research, Zadnik Stirn, L., Žerovnik, J., Kljajić Borštnar, M., Drobne, S., Eds., Bled, Slovenia, September 23-25, 2015, pp. 419-424.

29. Treynor J. (1965). How to Rate Management of Investment Funds. Harvard Business Review, January-February 1965, pp. 63-75. 
30.Wang, P., Moore, T. (2008). Stock market integration for the transition economies: timevarying conditional correlation approach. The Manchester School, Supplement 2008, pp. 116-133.

31.Zagreb Stock Exchange (2015). Trading data and statistics, Indices. Available at http://www.zse.hr [15 October 2015].

\section{About the author}

Tihana Škrinjarić graduated at the major Economics and post-graduated Statistical Methods for Economic Analysis and Forecasting at Faculty of Economics and Business, University of Zagreb. Currently, she is a PhD student at the same Faculty, where she works as a research and teaching assistant at the Department of Mathematics teaching the courses Mathematics, Econometrics, Mathematical Economics and Mathematical Methods for Managing Financial Assets. She won "Mijo Mirković" Prize and "CRORS Best Young Researcher Paper Award" in 2014, Rector's Award in 2010 and Dean's Award in 2009 and 2012. Up until now, list of her publications includes 36 publications (university textbooks, scientific and professional papers, etc.) of which she presented some on six international conferences. She was a Visiting Academic at Manchester Business School, University of Manchester for five months in 2015, at Centre for Analysis of Investment Risk and Division of Accounting and Finance. Her field of interests includes applied financial econometrics, with focus on stock markets, nonlinear econometric models in finance and risk modeling. Author can be contacted at tskrinjaric@efzg.hr. 